conservative in its programmatic tradition, making the transition late and only with some pain. This may well be so, but Lick was representative of an age and far from unique in the often difficult and bitter process of changing to an emphasis on individual projects informed by astrophysical theory.

To Osterbrock and his co-authors, Lick Observatory was vital only when it exploited properly its high mountain site and clear stable air. Thus they hail Keeler's upgrade of the 36-inch Crossley reflector and his creative use of it for observational astrophysics. The Crossley remained Lick's primary tool for direct photography and nebular spectroscopy, but it was soon overshadowed by George Ellery Hale's 60-inch reflector on Mount Wilson. As other observatories built larger reflectors, Lick's status continued to slip; only with the completion of the 120-inch Shane reflector, and the recruitment of staff able to explore both the observational and conceptual edges of modern astrophysics, did it fully revive.

For the past 20 years, Lick Observatory has been the Department of Astronomy at the University of California at Santa Cruz. Osterbrock and company provide a valuable narrative chronology of events that shows how and why this happened. Although at times the story is laboured more a 'who did what and when' than an intellectual journey - the staff and programmes of the observatory and how and why they changed over time are candidly and vividly portrayed.

My only complaint about Eye on the $S k y$ is that it is devoid of direct citations to sources. Writing a popular work, the authors did not wish to "clutter the text with references" (p. 274), feeling that sources cited in the aggregate in bibliographical notes should be sufficient for those motivated to dig further. More serious readers will find the practice frustrating. But that apart, both books do credit to the centenary of the Lick Observatory and are well worth reading for the complementary perspectives they provide.

David H. DeVorkin is Curator of Astronomy at the National Air and Space Museum, Smithsonian Institution, Washington, DC 20560, USA.

\section{Here, there and everywhere}

\section{Desmond King-Hele}

Infinite in all Directions. By Freeman J. Dyson. Bessie/Harper \& Row: 1988. Pp.321. \$19.95.

Freeman Dyson is among the few scientists who are comfortable roaming infinitely in all directions, and his new book lives up to its exacting title. He takes us on an exhilarating roller-coaster ride that runs from the farthest reaches of boundless space into the nutshell-world of the subatomic, and from life's origins to its present travails and faraway future. The book springs from the Gifford Lectures he gave at Aberdeen, Scotland, in 1985 under the title "In Praise of Diversity", but the material has been extended and rewritten.

Dyson begins by skipping round the physical Universe, telling us of events and ideas that appeal to him, and then offers three subtle and detailed chapters on the origin of life and its possible future. Aftet these essays on the infinite possibilities of the Universe, he turns to our "unbounded responsibilities" as custodians of life on a small planet, where we have "a heritage to cherish" and "a destiny to earn". Looking back at his own roots, he sees himself as an intellectual descendant of Richard Hakluyt, the sixteenth-century promoter of exploration; of William Blake, the prophet of freedom; and of Jules Verne, who set him "on the road to America and from there onward to Uranus".

Darting here and there as the title promises, Dyson next focuses on the idea that "quick is beautiful" in technology today: being able to react to change within three to five years is the key to success. A new and growing technology, he believes, "is usually small, quick and agile"; an overripe technology "cannot regain its lost youth". The virtues of the quick and the small re-emerge in the chapter entitled "Science and Space", and are contrasted with the vices of massive projects where the design has to be fixed ten years before the spacecraft operates. Dyson compares NASA's Hubble Telescope unfavourably with ESA's Hipparcos spacecraft. "Committees do harm merely by existing", he says, because the big and costly projects are always over-emphasized. Also committees work by extrapolation of current trends; but this is not effective for more than about ten years ahead, because "neither cleverness nor stupidity is predictable" and either may alter the climate of opinion irrevocably. So engineers need to dream, and the chapter "Engineers' Dreams" offers the committees some nightmares. Dyson's own dream is for a space mission to Uranus in 2016 by an Astrochicken, a symbiosis of plant, animal and electronic components. Launched as an egg, it will mature at its planetary destination and manoeuvre itself with the aid of a Bombardier beetle's chemical jet. Imagine a committee deliberating on that proposal!

From biological spacecraft, Dyson flips back to ponder power politics on Earth.
He likes the example of Austria, nonnuclear and neutral, and advocates the Austrianization of Germany. He hopes for a non-nuclear world, but not world government; and he is even-handed in his discussions of Star Wars and nuclear winter. These varied subjects are linked by his beliefs (apparently serious and not tongue-in-cheek) "that the universe is constructed according to a principle of maximum diversity" and that the laws of nature "are such as to make the universe as interesting as possible".

Whatever we may think of the maximum-diversity principle as a world-view, there is no denying its importance throughout this scintillating book that gives the lie to the literary wallahs who complain that scientists cannot write. And only a scientist could run over the Universe in a manner so easy and relaxed. Dyson is to be congratulated on making science interesting for an audience wider than scientists, and on writing much better than most of the literary pundits.

Some of the sparkle arises because Dyson cannot resist climbing out on a limb, and no one will agree with all that he says. For example, he candidly confesses to believing in a God "who grows with the universe and learns as it develops". For those who need a Deity, this concept of God as a super-Freeman-Dyson may perhaps be more attractive than many of the other Gods on offer in the world today. Dyson also goes out on a limb in trying to argue that science and religion are similar: this seems a libel on science, for religion has been and still is at the root of a large fraction of the world's wars, whereas science has not directly caused any, and only a few can be attributed to technological arrogance.

Differences of opinion on these wider issues are inevitable, and Dyson should not be blamed for his frank speaking. A more serious complaint, I think, is that his enthusiasm and personal touch - which together animate the book - do sometimes lead him to swallow theories rather uncritically, especially if their originators have visited him at Princeton. To mention one example, comets may possibly come from an unobservable "Oort Cloud", and this hypothetical cloud may have a "losscone" to explain periodicities. There is also a remote possibility that the Sun has a companion star (they call it Nemesis). But even the first two of these hypotheses are not "firmly based", as he says they are: they may soon evaporate like a puff of phlogiston. Enthusiasm brooks no ifs and buts. This book rides on its enthusiasms and, though the ride is pleasant, we often need to add our own ifs and buts.

Desmond King-Hele is a Deputy Chief Scientific Officer at the Royal Aircraft Establishment, Farnborough, Hampshire GU14 6TD, UK. Among other books he is author of Satellites and Scientific Research (1960) and Erasmus Darwin and the Romantic Poets (1986). 